\title{
Embolization of sacral tumors
}

\author{
Oren N. GotTfried, M.D., Meic H. Schmidt, M.D., And Edwin A. Stevens, M.D. \\ Departments of Neurosurgery and Radiology, University of Utah Health Sciences Center, Salt Lake \\ City, Utah
}

\begin{abstract}
The management of sacral tumors is challenging because of difficulties in accessing the lesion, the high rate of local recurrence, extensive vascularity causing significant intraoperative blood loss, resistance to radiation therapy, and risk of malignant transformation. Although surgery is the main treatment for many sacral tumors, embolization is a valuable primary and adjunctive therapy. Patients with benign lesions, including aneurysmal bone cysts and giant cell tumors, have responded to embolization with resolution of their symptoms and with ossification of their lesions. Embolization is used as a primary therapy for metastatic lesions and results in neurological improvement, reduced tumor size, and decreased spinal canal compromise. It is also used as an adjuvant therapy to reduce intraoperative blood loss and to aid in the resection of benign, malignant, and metastatic sacral lesions. It is important to note that embolization techniques are a valuable resource in the treatment of sacral tumors, and, overall, embolization should always be considered in patients with sacral tumors.
\end{abstract}

\section{KEY WORDS • embolization • sacrum • sacral tumor}

Typically, tumors of the sacrum are treated with surgery or radiotherapy. ${ }^{33}$ Sacral tumors are challenging to treat because of the difficulties involved in accessing the lesion, local recurrences, significant vascularity making a complete resection difficult, resistance to radiotherapy (as seen in chordomas), and potential for malignant transformation. ${ }^{33,37}$ There are several adjuvant therapies available for treating sacral tumors, including chemotherapy, chemotherapy with hyperthermia, and cryosurgery. ${ }^{37}$ Embolization of sacral tumors is a useful adjuvant therapy and aids in the surgical management of these lesions. Embolization techniques are used to reduce intraoperative blood loss for benign, malignant, and metastatic lesions of the sacrum. These techniques are also used as a primary and definitive treatment modality for benign lesions, including giant cell tumors and aneurysmal bone cysts. Embolization can be effective as a palliative treatment for metastatic lesions that cause neurological compromise or pain. In general, it is important for the surgeon to understand that embolization techniques are a valuable resource for treating sacral tumors. The authors review the literature regarding the techniques and indications for embolization of sacral tumors.

Abbreviation used in this paper: PVA = polyvinyl alcohol.

\section{TECHNICAL CONSIDERATIONS}

There are many highly vascular sacral tumors. If a vascular lesion is suspected based on presentation and imaging, then preoperative angiography should be performed to characterize the vascular anatomy and to determine if the lesion would be amenable to embolization. ${ }^{37}$ Of note, sacral tumors may have significant collateral circulation, and tumor neovascular recruitment may induce the formation of an extensive lumbosacral collateral arterial network. Therefore, knowledge of these interconnections is imperative prior to performing an embolization procedure. ${ }^{37}$

Once the decision is made to proceed with embolization, it is important to determine if a proximal arterial occlusion or embolization within the lesion is necessary. Occlusion at the level of the medium-sized vessels allows collateral circulation to restore flow immediately after embolization. Occlusion of smaller vessels results in slower constitution of collateral pathways, but there is a potential for tissue ischemia. Selective delivery of an embolic agent is desirable to minimize unwanted collateral vessel occlusion and subsequent tissue infarction and necrosis. A coaxial catheter system is used to achieve a safe selective catheter position. ${ }^{15}$ If selective vascular delivery is not possible, then direct percutaneous puncture techniques 
may be necessary to obtain a selective embolization placement. ${ }^{5,9}$ For example, it is possible to use percutaneous intralesional injections of alcohol embolizing emulsions when embolization is too risky because the blood supply of the tumor is close to the vasculature supplying neural tissue. ${ }^{5,9}$

There are several other embolic agents available. The choice of embolic material is based on the territory to be embolized, the permanence of occlusion needed, and the possibilities for selective delivery of an embolic agent via a transcatheter or direct percutaneous puncture route. Typically, Gelfoam, PVA particles, and coils are used for embolization; however, other agents include tissue adhesive, ethanol, and microfibrillar collagen. Generally, embolization is believed to be safe and effective regardless of the agent used, although it is thought that embolization is ineffective if proximal occlusion of large vessels is performed without penetrating the distal tumor architecture. ${ }^{28}$

Gelfoam is a small-particle (40-60 $\mu \mathrm{m})$ embolic agent administered via a transcatheter technique in cases requiring superselective positioning in the sacral region. ${ }^{37}$ Its small particle size makes inadvertent small-vessel occlusion possible; therefore, it should only be used if superselective positioning can be achieved. ${ }^{14,37}$ Gelfoam is a temporary occlusion; it is degraded by enzymes and recanalization typically occurs between 7 and 10 days. ${ }^{14,15,37}$ When Gelfoam is used for preoperative embolization, surgery should be performed within 24 hours to prevent recanalization. ${ }^{13}$

Polyvinyl alcohol particles are commonly used for distal embolization to occlude vessels within the tumor. ${ }^{15,24}$ These particles are inert, water insoluble, nonabsorbable, and occlude tumor vessels proximal to or at the capillary bed. ${ }^{24,25,28}$ They are suspended in nonionic contrast material, which allows fluoroscopic visualization of their progress. ${ }^{24}$ The particle size ranges from 45 to $500 \mu \mathrm{m} .{ }^{37}$ Although there is a range in the size of the particles, Manke, et al., ${ }^{19}$ showed that there is no significant difference in intraoperative blood loss when particles smaller than or larger than $250 \mu \mathrm{m}$ are used. Gelfoam and PVA particles may be used in combination.

Coils are used for proximal occlusion and are useful because, unlike particles, they do not have the potential for peripheral dissemination; in addition, they produce permanent occlusion. ${ }^{14,28}$ Coils are also used to protect uninvolved distal vessels. ${ }^{15,19}$ Coils may be used as the only occlusive agent or in conjunction with other embolic material. Of note, Berkefeld, et al., ${ }^{1}$ found that coils were less efficacious for decreasing operative blood loss in spinal column tumors compared with PVA particles or PVA particles and coils.

The timing of preoperative embolization is also an important technical consideration. Generally, it is recommended that embolization be performed as close as possible to the time of surgery. Typically, minimal blood loss occurs when surgery is performed within 24 to 48 hours after embolization. ${ }^{5,13,14,28}$

\section{TUMOR SELECTION}

Benign Lesions. Aneurysmal bone cysts and giant cell tumors are two benign lesions that may arise in the sacrum and are difficult to treat. Surgery on giant cell tumors of the sacrum is technically difficult, and complicated by extensive hemorrhage and neurological compromise. ${ }^{17}$ Additionally, radiotherapy produces a limited benefit and is associated with a risk of malignant change. ${ }^{17}$ Treatment is further complicated by the high rate of recurrence of these tumors. ${ }^{17}$ Aneurysmal bone cysts of the sacrum are difficult to manage because of their rapid growth, extensive destruction of bone, high risk of local recurrence, wide extraosseous tumor masses, and significantly vascular nature. ${ }^{23}$

Fortunately, embolization techniques have aided the treatment of aneurysmal bone cysts and giant cell tumors. Like malignant lesions, these benign lesions can be embolized prior to resection to reduce blood loss. ${ }^{8,15,23} \mathrm{Em}$ bolization can be used to treat pain from aneurysmal bone cysts and giant cell tumors ${ }^{34}$ and can also serve as an adjuvant therapy to surgery or radiotherapy. ${ }^{6,8,10,15,18,23,37}$ After other modes of therapy fail in the treatment of unresectable giant cell tumors and aneurysmal bone cysts, embolization may be successful. ${ }^{6,8,10}$ Chuang, et al., 6 treated 10 patients with inoperable giant cell tumors or aneurysmal bone cysts in whom other treatments had failed. Seven patients were relieved of pain, in five patients there was tumor resolution, and, overall, six responded to the therapy. It is important to note that these lesions respond to embolization as a primary and definitive treatment and there have been many reports in which the procedure served as an alternative to surgery. ${ }^{6,7,15,17,18,20,30}$ Lackman, et al., ${ }^{17}$ found that four of five patients with giant cell tumors of the sacrum treated exclusively with embolization experienced resolution of symptoms, arrested tumor growth, and recurrence. Lin, et al., ${ }^{18}$ reported similar results in 14 of 18 patients with giant cell tumors of the sacrum treated with serial embolization. De Cristofaro, et al., ${ }^{7}$ and Konya and Szendroi ${ }^{15}$ found that the majority of patients with aneurysmal bone cysts responded to singletreatment embolization with complete resolution of symptoms and ossification of the lesion. Konya and Szendroi ${ }^{15}$ noted remineralization 2 to 4 months after vessel occlusion and reconstruction at 5 to 8 months. Overall, the recurrence rate after embolization for aneurysmal bone cysts and giant cell tumors lesions is low, and recurrence is managed with repeated embolization., ${ }^{7}, 17$

Serial embolization of these lesions is typically performed at 4- to 6-week intervals until symptomatic improvement occurs or the tumor's vascularity disappears. ${ }^{17}$ Success of embolization is confirmed by postprocedure angiography, magnetic resonance imaging, or computerized tomography scanning. ${ }^{17}$ For example, complete ossification after treatment of aneurysmal bone cysts is considered a treatment success. ${ }^{15}$ Reccurrence of symptoms is followed by a reevaluation with magnetic resonance imaging, computerized tomography, or angiography. If there is an increase in tumor size or evidence of increased vascularity, then embolization therapy is restarted. ${ }^{7}$ Other treatment options are used for lesions that do not respond to embolization.

There are other benign lesions of the sacrum that are treated with embolization therapy including osteoid osteoma, osteoblastoma, and hemangiomas. ${ }^{2,4,8,11}$ Biagini, et al., ${ }^{2}$ and Capanna, et al., ${ }^{4}$ noted that preoperative emboli- 
zation is indicated for aggressive osteoid osteomas and osteoblastomas. Preoperative embolization reduces blood loss in the surgery of spinal hemangiomas. ${ }^{11}$

Neural Tumors. Some tumors arising from the neural elements are vascular and responsive to embolization. Embolization is useful as a preoperative measure to reduce the duration of the procedure and to reduce blood loss during surgery of presacral schwannomas. ${ }^{29}$ Additionally, preoperative embolization has been performed in a sacral meningioma. ${ }^{12}$ Shi, et al.,${ }^{25}$ used preoperative embolization for several intradural spinal tumors, including a hemangioblastoma, meningioma, and schwannoma, and noted decreased intraoperative bleeding and easier resection due to a defined plane between the tumor and neural tissue.

Malignant Lesions. Most primary malignant tumors of the sacrum demonstrate increased vascularity, although the most common one, the chordoma, has variable vascularity. ${ }^{27,31}$ Angiography is useful in determining if a chordoma is hypervascular and evaluating whether embolization would be beneficial as a preoperative measure. ${ }^{36}$ Wang, et al., ${ }^{35}$ performed selective arterial embolization prior to tumor resection in 15 primary thoracolumbar spinal tumors including malignant schwannomas, chordoma, fibrous xanthosarcoma, malignant fibrohistocytoma, osteosarcoma, Ewing sarcoma, myeloma, and leiomyosarcoma. There were satisfactory results after embolization: in all patients intraoperative blood loss was reduced and operative time was shortened; there was a clear operative field for tumor resection.

Metastatic Tumors. Preoperative embolization of hypervascular metastatic lesions reduces intraoperative blood loss and improves the surgeon's ability to resect the tumor, allowing more aggressive resection. It can also reduce mass effect, arrest tumor growth, alleviate pain, and shorten hospital stay. ${ }^{14,24,32}$ Preoperative embolization has been shown to reduce intraoperative blood loss for renal cell carcinoma, thyroid carcinoma, sarcoma, and metastatic melanoma to the spine. ${ }^{3,13,14,19,21,24,26,28,32}$ Several authors have noted reduced blood loss by one third to two thirds for metastatic spine lesions treated preoperatively with embolization. ${ }^{1,13,14,19,21}$ Hess, et al., ${ }^{14}$ and Smith, et al. ${ }^{28}$ noted that after embolization, no subsequent surgeries had to be terminated because of excessive blood loss. Even partial embolization can significantly reduce intraoperative blood loss. ${ }^{19}$

Embolization has also been used as a primary treatment for symptomatic relief from metastatic disease. O'Reilly, et al.,22 treated four patients with transarterial catheter embolization for solitary vertebral metastasis from renal cell carcinoma, who presented with acute spinal cord or nerve root compression. All patients experienced neurological improvement at 24 hours and this improvement lasted for more than 12 weeks. ${ }^{22}$ Kuether, et al., ${ }^{16}$ noted increased strength, improved sensation, and decreased spinal cord compression in a patient with metastatic renal cell carcinoma to the thoracic spine treated exclusively with embolization. In addition, this patient's sacral bone metastasis was successfully treated with embolization. At 5-month follow up, the patient's lesions were stable in size and the patient did not require spinal decompression. Other metastatic spinal lesions, including thyroid carcinoma, can respond to palliative embolization therapy with resulting neurological improvement. ${ }^{26}$

\section{COMPLICATIONS}

Most patients experience nausea, emesis, low-grade fever, and pain after embolization, which usually last 3 to 7 days. ${ }^{10,18,34,37}$ Ischemic neuropathy can result in motor and sensory deficits in the pelvis and lower extremities, and it is a potential complication of any pelvic embolization. ${ }^{18,37}$ Additionally, the neuraxis or the sacral plexus of nerves can be injured. ${ }^{37}$ Therefore, care must be taken to identify and avoid embolization of the neurovascular anatomy. Rectal ischemia can result from superior hemorrhoidal artery embolization. ${ }^{37}$ Any embolization of sacral tumors may result in injury to nontargeted tissue including muscle infarction, injury to the skin, or injury to the colon or other organs. ${ }^{37}$

\section{CONCLUSIONS}

Embolization is a valuable primary and adjunctive treatment option for many sacral tumors. Close consultations among the neurosurgeon, the radiation oncologist, and the interventionalist will lead to more applications of embolization techniques, thereby enhancing the treatment of sacral tumors.

\section{References}

1. Berkefeld J, Scale D, Kirchner J, et al: Hypervascular spinal tumors: influence of the embolization technique on perioperative hemorrhage. AJNR 20:757-763, 1999

2. Biagini R, Orsini U, Demitri S, et al: Osteoid osteoma and osteoblastoma of the sacrum. Orthopedics 24:1061-1064, 2001

3. Broaddus WC, Grady MS, Delashaw JB Jr, et al: Preoperative superselective arteriolar embolization: a new approach to enhance resectability of spinal tumors. Neurosurgery 27: 755-759, 1990

4. Capanna R, Ayala A, Bertoni F, et al: Sacral osteoid osteoma and osteoblastoma: a report of 13 cases. Arch Orthop Trauma Surg 105:205-210, 1986

5. Chiras J, Cognard C, Rose M, et al: Percutaneous injection of an alcoholic embolizing emulsion as an alternative preoperative embolization for spine tumor. AJNR 14:1113-1117, 1993

6. Chuang VP, Soo CS, Wallace S, et al: Arterial occlusion: management of giant cell tumor and aneurysmal bone cyst. AJR 136:1127-1130, 1981

7. De Cristofaro R, Biagini R, Boriani S, et al: Selective arterial embolization in the treatment of aneurysmal bone cyst and angioma of bone. Skeletal Radiol 21:523-527, 1992

8. Dick HM, Bigliani LU, Michelsen WJ, et al: Adjuvant arterial embolization in the treatment of benign primary bone tumors in children. Clin Orthop 139: 133-141, 1979

9. Doppman JL, Oldfield EH, Heiss JD: Symptomatic vertebral hemangiomas: treatment by means of direct intralesional injection of ethanol. Radiology 214:341-348, 2000

10. Eftekhari F, Wallace S, Chuang VP, et al: Intraarterial management of giant-cell tumors of the spine in children. Pediatr Radiol 12:289-293, 1982

11. Esparza J, Castro S, Portillo JM, et al: Vertebral hemangiomas: spinal angiography and preoperative embolization. Surg Neurol 10:171-173, 1978

12. Feldenzer JA, McGillicuddy JE, Hopkins JW: Giant sacrolumbar meningioma. Case report. J Neurosurg 72:951-954, 1990

13. Gellad FE, Sadato N, Numaguchi Y, et al: Vascular metastatic 
lesions of the spine: preoperative embolization. Radiology 176: 683-686, 1990

14. Hess T, Kramann B, Schmidt E, et al: Use of preoperative vascular embolisation in spinal metastasis resection. Arch Orthop Trauma Surg 116:279-282, 1997

15. Konya A, Szendroi M: Aneurysmal bone cysts treated by superselective embolization. Skeletal Radiol 21:167-172, 1992

16. Kuether TA, Nesbit GM, Barnwell SL: Embolization as treatment for spinal compression from renal cell carcinoma: case report. Neurosurgery 39:1260-1263, 1996

17. Lackman RD, Khoury LD, Esmail A, et al: The treatment of sacral giant-cell tumours by serial arterial embolisation. J Bone Joint Surg Br 84:873-877, 2002

18. Lin PP, Guzel VB, Moura MF, et al: Long-term follow-up of patients with giant cell tumor of the sacrum treated with selective arterial embolization. Cancer 95:1317-1325, 2002

19. Manke C, Bretschneider T, Lenhart M, et al: Spinal metastases from renal cell carcinoma: effect of preoperative particle embolization on intraoperative blood loss. AJNR 22:997-1003, 2001

20. Murphy WA, Strecker EB, Schoenecker PL: Transcatheter embolisation therapy of an ischial aneurysmal bone cyst. J Bone Joint Surg Br 64:166-168, 1982

21. Olerud C, Jonsson H Jr, Lofberg AM, et al: Embolization of spinal metastases reduces peroperative blood loss. 21 patients operated on for renal cell carcinoma. Acta Orthop Scand 64: 9-12, 1993

22. O'Reilly GV, Kleefield J, Klein LA, et al: Embolization of solitary spinal metastases from renal cell carcinoma: alternative therapy for spinal cord or nerve root compression. Surg Neurol 31:268-271, 1989

23. Pogoda P, Linhart W, Priemel M, et al: Aneurysmal bone cysts of the sacrum. Clinical report and review of the literature. Arch Orthop Trauma Surg 123:247-251, 2003

24. Prabhu VC, Bilsky MH, Jambhekar K, et al: Results of preoperative embolization for metastatic spinal neoplasms. J Neurosurg (Spine 2) 98:156-164, 2003

25. Shi HB, Suh DC, Lee HK, et al: Preoperative transarterial embolization of spinal tumor: embolization techniques and results. AJNR 20:2009-2015, 1999

26. Smit JW, Vielvoye GJ, Goslings BM: Embolization for verte- bral metastases of follicular thyroid carcinoma. J Clin Endocrinol Metab 85:989-994, 2000

27. Smith J, Ludwig RL, Marcove RC: Sacrococcygeal chordoma. A clinicoradiological study of 60 patients. Skeletal Radiol 16: 37-44, 1987

28. Smith TP, Gray L, Weinstein JN, et al: Preoperative transarterial embolization of spinal column neoplasms. J Vasc Interv Radiol 6:863-869, 1995

29. Stecken J, Bardaxoglou E, Touquet S, et al: [Giant sacral schwannoma with pelvic extension. Therapeutic strategy. Apropos of a case.] Neurochirurgie 42:294-299, 1996 (Fr)

30. Suby-Long T, Bos GD, Rosch J: Biopsy proven eradication of an aneurysmal bone cyst treated by superselective embolization: a case report. Cardiovasc Intervent Radiol 11:292-295, 1988

31. Sundaresan N: Chordomas. Clin Orthop 204:135-142, 1986

32. Sundaresan N, Choi IS, Hughes JE, et al: Treatment of spinal metastases from kidney cancer by presurgical embolization and resection. J Neurosurg 73:548-554, 1990

33. Sung HW, Shu WP, Wang HM, et al: Surgical treatment of primary tumors of the sacrum. Clin Orthop 215:91-98, 1987

34. Wallace S, Granmayeh M, deSantos LA, et al: Arterial occlusion of pelvic bone tumors. Cancer 43:322-328, 1979

35. Wang J, Lu S, Hu Y, et al: [Selective arterial embolization for the treatment of thoracolumbar spinal tumor.] Zhonghua Wai Ke Za Zhi 37:724-726, 1999 (Chn)

36. Winants D, Bertal A, Hennequin L, et al: [Imaging of cervical and thoracic chordoma. Apropos of 2 cases.] J Radiol 73: 169-174, 1992 (Fr)

37. Yakes WFJ, Carrasco CH, Luethke JM: Embolization of lumbosacral lesions, in Doty JR, Rengachary SS (eds): Surgical Disorders of the Sacrum. New York: Thieme, 1994, pp 294-308

Manuscript received June 19, 2003.

Accepted in final form July 10, 2003.

Address reprint requests to: Oren N. Gottfried, M.D., Department of Neurosurgery, University of Utah Medical Center, 30 North 1900 East, Suite 3B409, Salt Lake City, Utah 84132. email: Oren.Gottfried@hsc.utah.edu. 